\title{
Silencing of Kex2 Significantly Diminishes the Virulence of Cryphonectria parasitica
}

\author{
Debora Jacob-Wilk, Massimo Turina, Pam Kazmierczak, and Neal K. Van Alfen \\ Department of Plant Pathology, University of California, Davis 95616, U.S.A.
}

Submitted 28 April 2008. Accepted 7 October 2008.

Cryphonectria parasitica is the causal agent of chestnut blight. Infection of this ascomycete with Cryphonectria hypovirus 1 (CHV1) results in reduction of virulence and sporulation of the fungus. The virus affects fungal gene expression and several of the CHV1 downregulated genes encode secreted proteins that contain consensus Kex 2 processing signals. Additionally, CHV1 has been shown to colocalize in infected cells primarily with fungal trans-Golgi network vesicles containing the Kex 2 protease. We report here the cloning, analysis, and possible role of the $C$. parasitica Kex2 gene (CpKex2). CpKex2 gene sequence analysis showed high similarity to other ascomycete kexin-like proteins. Southern blot analyses of CpKex 2 showed a single copy of this gene in the fungal genome. In order to monitor the expression and evaluate the function of $C p K e x 2$, antibodies were raised against expressed protein and Kex2silenced mutants were generated. Western blots indicate that the Kex 2 protein was constitutively expressed. Growth rate of the fungus was not significantly affected in Kex2silenced strains; however, these strains showed reduced virulence, reduced sexual and asexual sporulation, and reductions in mating and fertility. The reduced virulence was correlated with reduced Kex2 enzymatic activity and reduced relative mRNA transcript levels as measured by real time reverse-transcriptase polymerase chain reaction. These results suggest that secreted proteins processed by Kex2 are important in fungal development and virulence.

Infection of the chestnut blight fungus, Cryphonectria parasitica, with Cryphonectria hypovirus 1 (CHV1) results in reduced virulence (Heiniger and Rigling 1994). Interest in the understanding of this fungal-viral interaction stems from the biological control of this important plant pathogen and its potential as a model for the study of fungal virulence and fungal development in general. Infection of $C$. parasitica with $\mathrm{CHV} 1$ affects developmental processes of the fungus but growth rate in culture is not affected by the virus, indicating that the perturbation of development is not the result of general debilitation of the fungus (McCabe and Van Alfen 2001; McCabe et al. 1999). The infected fungus remains in a vegetative state, unable to initiate developmental processes necessary to invade its host (McCabe and Van Alfen 2001).

CHV1 is a double-stranded (ds)RNA virus that has been found to replicate in association with fungal vesicles. Virus

Current address of M. Turina: Istituto di Virologia Vegetale, CNR Torino, Strada delle Cacce 73, 10135 Torino, Italy.

Corresponding author: D. Jacob-Wilk; Telephone: +1.530.754.5500; Fax: +1.530.752.5674; E-mail:dkwilk@ucdavis.edu
dsRNA, RNA-dependant RNA polymerase activity, the viral helicase, and the virus proteinase p29 co-purify with this fungal vesicle fraction which was identified as part of the fungal trans-Golgi network (TGN) because of its association with the fungal TGN marker Kex2 (Fahima et al. 1993; Jacob-Wilk et al. 2006). The cytoplasm of CHV1-infected strains contain increased amounts of these membrane-enclosed vesicles (Newhouse et al. 1983, 1990). Uninfected strains of the fungus contain smaller numbers of similar vesicles with comparable composition but which lack viral proteins (Hansen et al. 1985).

In previous studies, through differential expression screens of proteins and mRNAs, CHV1 was observed to downregulate a number of gene products in $C$. parasitica (Powell and Van Alfen 1987a and b) at the transcription level (Kazmierczak et al. 1996). Three of these gene products have encoded signals for post-translational processing by a Kex2-like endoprotease. These fungal gene products are a laccase, hypothesized to be involved in the development of fruiting bodies (Choi et al. 1992; Leatham and Stahmann 1981; Rigling and Van Alfen 1991, 1993); cryparin, an abundant hydrophobin located on the surface of fruiting bodies (Kazmierczak et al. 1996, 2005; Zhang et al. 1994); and fungal pheromones necessary for mating (Turina et al. 2003). The Kex 2 processing signal common to all three gene products is encoded as part of the propeptide and directs the cleavage of the propeptide by a serine protease like the Saccharomyces cerevisiae Kex 2 protease (Fig. 1). The Kex 2 protease is a transmembrane calcium-dependent protease, which cleaves on the carboxyl side of Lys-Arg and ArgArg sequences in polypeptide precursors. Those kexins that have been already described in fungi are located in the TGN and prevacuolar compartment where they process proproteins involved in cell wall maintenance and remodeling (Basco et al. 1996; Brickner and Fuller 1997), proteins involved in hyphal formation (Wösten et al. 1996), processing of the $\alpha$-type mating pheromone precursor, M1-encoded killer toxin (Julius et al. 1984), zymogens of secreted proteases (Newport and Agabian 1997), lipases (Pignède et al. 2000), and polysaccharide-degrading enzymes (Goller et al. 1998; Iguchi et al. 1997). The Kex 2 protein in Candida albicans, an opportunistic pathogen, was shown to be involved in the processing necessary for two of the best-characterized virulence-related processes: hyphal formation and proteinase secretion (Newport and Agabian 1997; Newport et al. 2003).

The discovery that several of the CHV1 downregulated fungal genes encode for secreted proteins containing the Kex2 processing consensus and our identification of Kex 2 containing fungal vesicles as the site of CHV1 replication suggests that the virus may adversely affect fungal protein secretion, specifically those proteins which are Kex2 processed. In order to further examine the role of Kex2 in Cryphonectria parasitica virulence and development, we cloned the Kex2 gene, produced 
antibodies against the bacterially expressed recombinant protein, and characterized several Kex2-silenced strains. Present results indicate that Kex 2 is an essential factor in fungal virulence and development of $C$. parasitica.

\section{RESULTS}

\section{C. parasitica Kex2 sequence analysis.}

C. parasitica Kex2 (CpKex2) gene cloning was described elsewhere (Jacob-Wilk et al. 2006) and its nucleotide sequence has been submitted to GenBank with accession number DQ219470. Sequence analysis showed high degrees of identity and similarity to other kexin-like and hypothetical proteins, respectively, from Neurospora crassa (63 to 76\%), Magnaporthe grisea (59 to $72 \%$ ), Gibberella zeae (59 to 73\%), Aspergillus fumigatus (52 to 68\%), A. nidulans (54 to 69\%), and A. niger (53 to 68\%). It contains an N-terminal domain with a signal peptide of 18 amino acids and a prosequence of 84 residues preceding a region of homology to peptidase $\mathrm{S} 8$ from the subtilase family of serine proteases between residues 165 and 342 . Following the subtilisin domain is a sequence of 134 residues spanning amino acids 477 to 611 , the $\mathrm{P}$ domain, a unique feature of the eukaryotic subtilisin-like proprotein convertases, followed by a predicted transmembrane-spanning domain between residues 713 and 731 , close to the $C$ terminus. The CpKex 2 open reading frame (ORF) is interrupted by a 76-bp intron positioned between bases 1,928 and 2,004 on the genomic sequence. The intron is in a conserved position relative to the KexB gene from $A$. niger and PbKex2 from Paracoccidioides brasiliensis (Jalving et al. 2000; Venancio et al. 2002). Due to the high sequence similarity, its highly conserved cata- lytic triad Asp-His-Ser, and its overall domain conservation with other fungal KexB genes and proteins, the gene was designated $C p K e x 2$. A schematic representation of the protein domains found on CpKex 2 is shown in Figure 2.

\section{Construction and characterization \\ of CpKex2-silenced mutants.}

Confirmation of $C p K e x 2$ function was attempted by targeted gene disruption; however, attempts to produce a $C p K e x 2$ deletion $(\triangle C p K e x 2)$ were futile. Transformation with different constructs and screening of more than 1,000 transformants produced no Kex 2 knock-outs as confirmed by Southern blots (not shown). Thus, an induced RNA silencing of the gene was attempted. C. parasitica EP67 spheroplasts were transformed with a silencing vector designed to express a hairpin RNA copy of a CpKex2 gene fragment (Fig. 3A). Transformants containing the silencing vector were selected on hygromycincontaining potato dextrose agar with methionine and biotin (PDAmb). Two independent transformations were performed and 30 and 22 mutants were recovered from the first and second transformation, respectively. In total, 46 mutants were screened with a Kex2 enzymatic assay (as described below). Several mutants showing decreased levels of Kex2 enzymatic activity compared with wild-type EP67 were taken for further phenotypic characterization. Those with the lowest levels of Kex2 enzymatic activity, named Mut-G, and with a reduction in activity in between the one observed on the wild-type strain and Mut-G, named Mut-P, were selected (data not shown). These two mutants were single spored, observed for stability of the phenotype and subjected to further characterization in this study. Mock mutants were transformed with the same

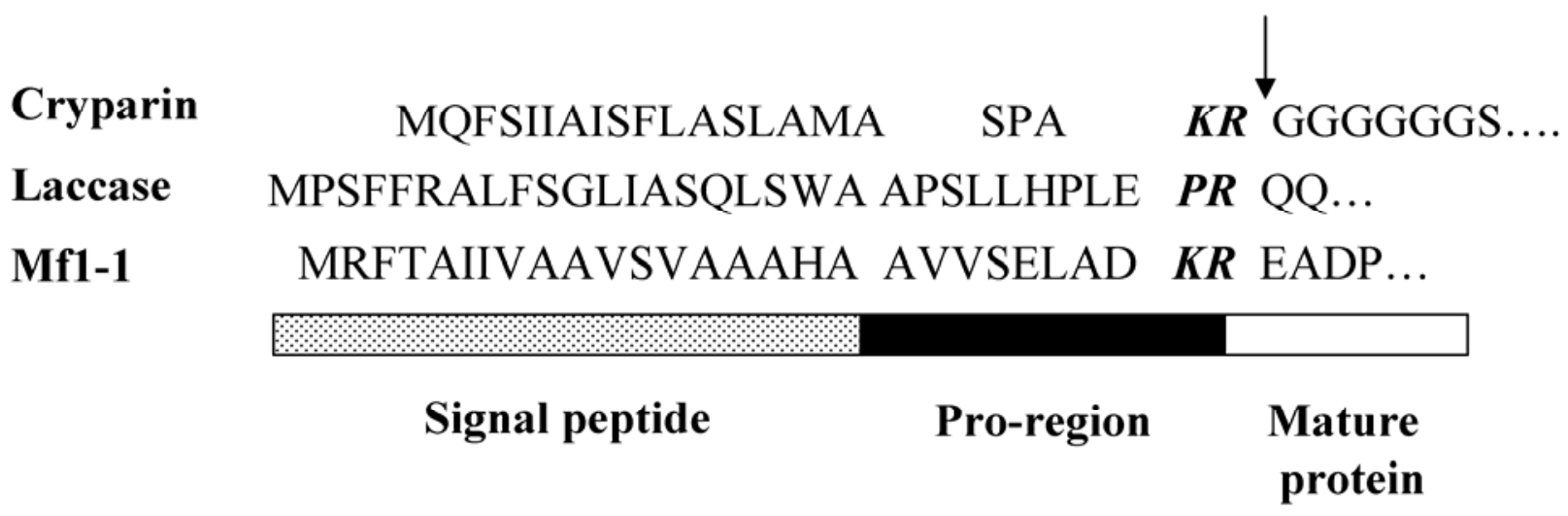

Fig. 1. N-terminal amino acid sequences and processing of Cryphonectria parasitica proteins that are downregulated upon Cryphonectria hypovirus 1 infection and which contain Kex2 processing signals. Arrow shows site of putative Kex2 processing.

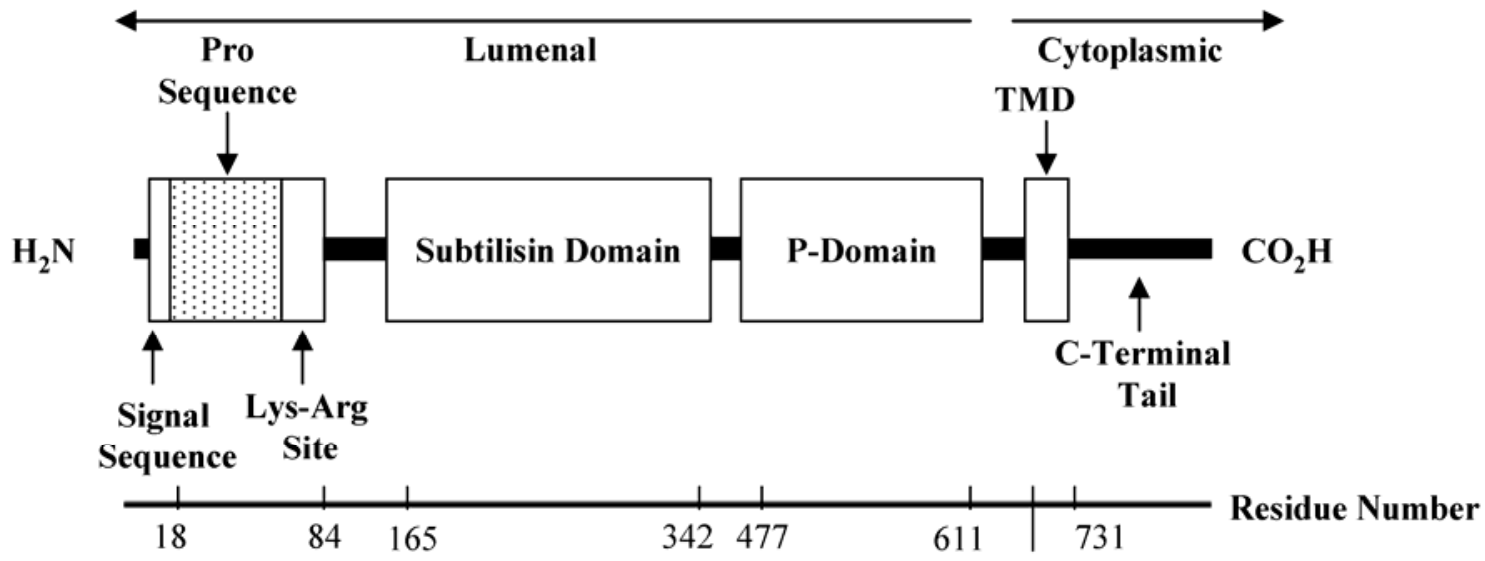

Fig. 2. Schematic representation of $\mathrm{CpKex} 2$ protein domains and structural motifs. $\mathrm{TMD}=$ transmembrane domain. 


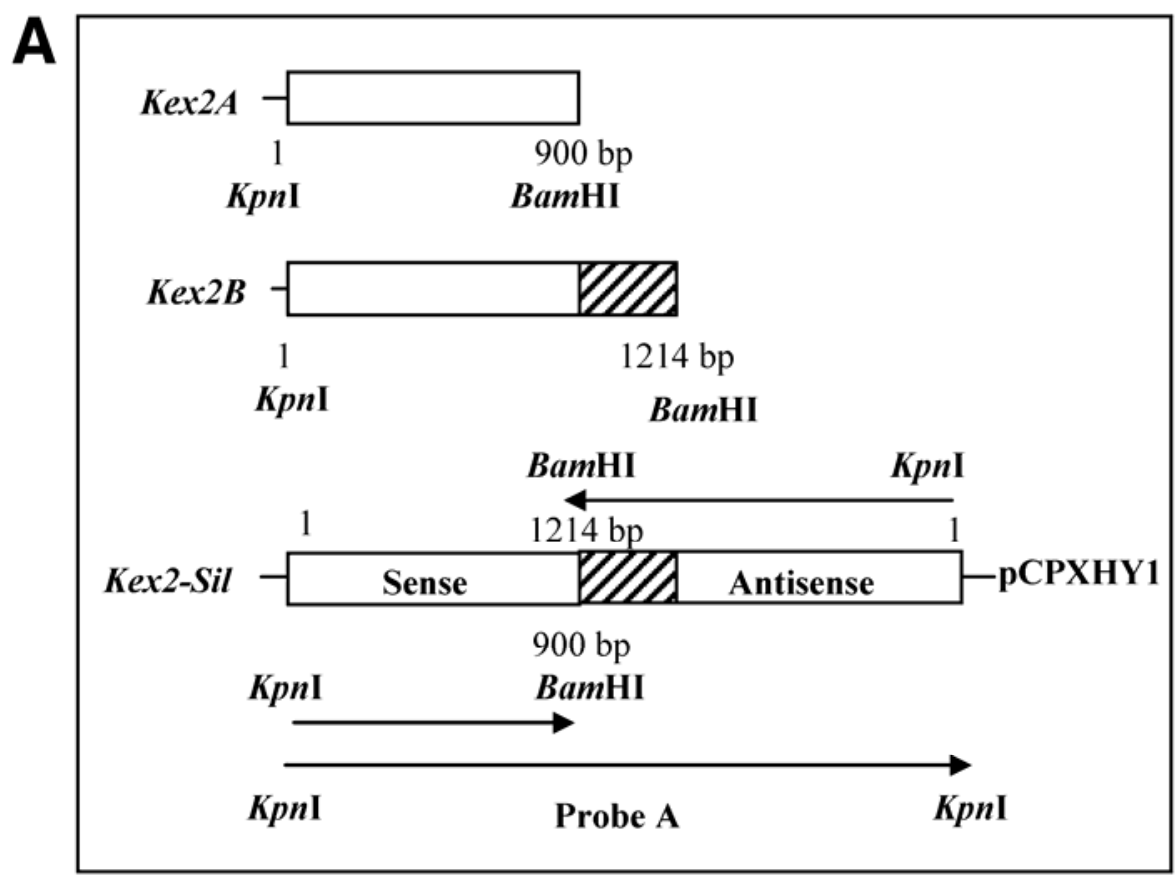

B
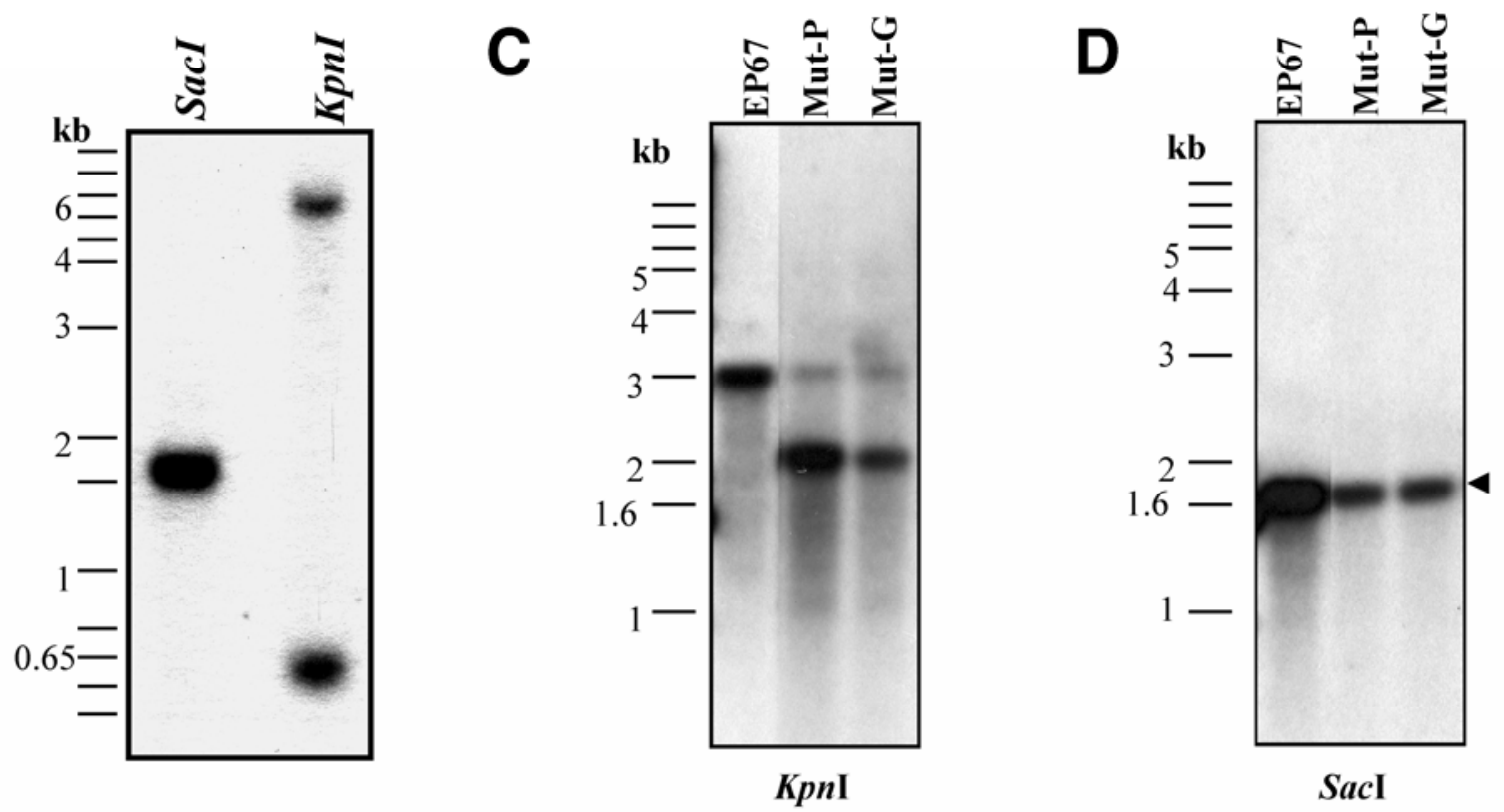

E

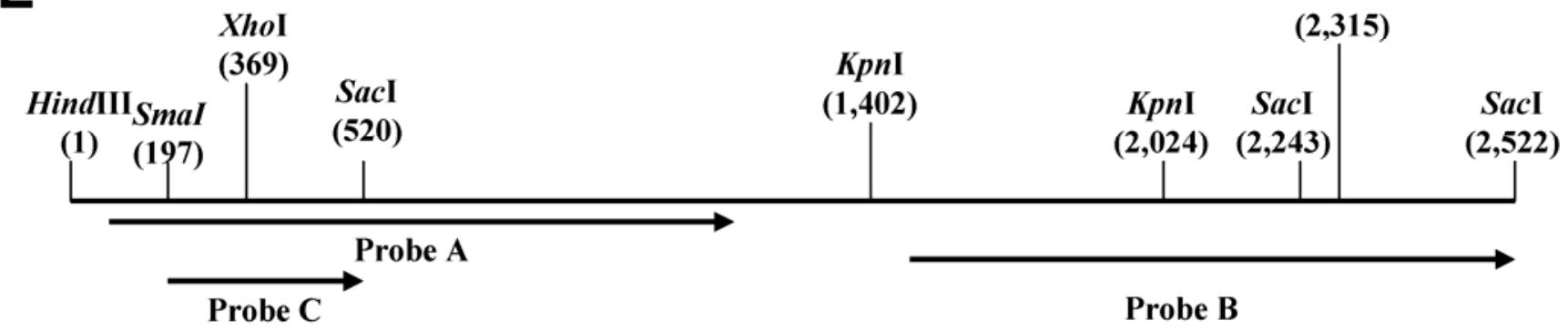

SacI

$(\mathbf{2 , 3 1 5 )}$

Fig. 3. A, Silencing construct diagram. A 900-bp fragment spanning bases -200 to 700 (Kex2A) and a 1,214-bp fragment spanning bases -200 to 1,014 $(\operatorname{Kex} 2 B)$ on the $\operatorname{Kex} 2$ genomic sequence were polymerase chain reaction cloned. The $\operatorname{Kex} 2 B$ fragment was then ligated in an inverted orientation to $K e x 2 A$, forming an inverted repeat separated by a 314-bp spacer fragment, created artificially by the noncomplementary DNA sequence amplified in the Kex $2 B$ fragment ( 900 to $1,214 \mathrm{bp}$ ). The inverted repeat was then cloned into vector pCPXHY1 containing the Cryphonectria parasitica gdp-1 promoter and terminator and hygromycin as a selective marker. B, Southern blot analysis of control EP67. Genomic DNA of wild-type EP67 was digested with SacI or $K p n I$ and hybridized with probe B. Genomic DNA of silenced mutants and wild-type strains were digested with C, KpnI or D, SacI and probed with Kex2 gene fragments, probe A and probe B, respectively. C, The 2,114-bp band represents the transcriptional unit of hairpin RNA used for silencing inserted in the genome. D, The closed triangle represents a 1,723-bp fragment corresponding to the expected wild-type Kex2 gene. E, Partial restriction map of genomic Kex 2 sequence and schematic representation of probes used. 
vector fused to green fluorescent protein (GFP) and selected for hygromycin resistance and green fluorescence before further characterization. Southern blot analyses of $C p K e x 2$ showed a single copy of this gene in the fungal genome (Fig. 3B). Restriction digestion reactions of wild-type EP67 genomic DNA with SacI or KpnI were blotted and hybridized to probe B (Fig. $3 \mathrm{E})$. A single band was detected on the SacI digestion of approximately $1,723 \mathrm{bp}$ as expected from the restriction of SacI at position 520 and 2,243 on the CpKex2 genomic sequence. We were never able to detect two smaller expected bands of 72 and $207 \mathrm{bp}$, the product of restrictions at $S a c \mathrm{I}$ at 2,243 and 2,315 , and 2,315 with 2,522 ; we attribute this to their small size and the fact that agarose percentage was low $(0.7 \%)$. Restriction digestion with $K p n I$ resulted in two detected bands: one of $622 \mathrm{bp}$, as expected from restrictions at KpnI at position 1,402 and 2,024, and the other of unknown size, the result of the restriction of $K p n I$ at position 2,024 and the next KpnI site on the $C$. parasitica genome, outside the gene toward its $3^{\prime}$ end. This band was shown to be between 6,000 and 7,000 bp. Both restriction results are indicative of a single-copy gene. Further analysis of the KpnI restriction with probe A (Fig. 3C)
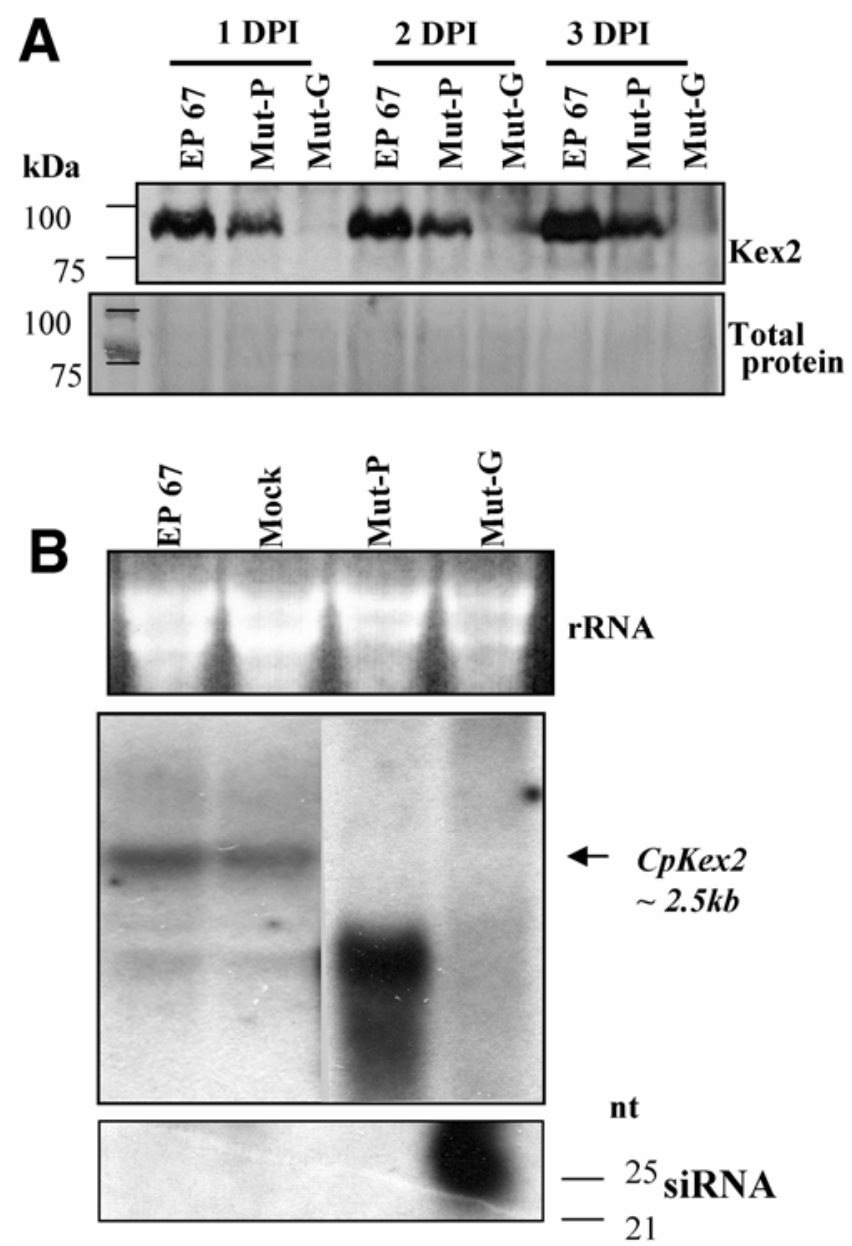

Fig. 4. Western, Northern, and siRNA blot analysis of selected Kex2silenced transformants. A, Western blot analysis of lysates prepared from control, virulent EP67 strain, and silenced strains Mut-P and Mut-G at 1, 2 , and 3 days postinoculation (DPI) probed with anti-Kex2 antisera. Migration position of molecular weight markers is indicated on the left. $\mathbf{B}$, Northern blot analysis of the Kex 2 mRNA expression of the silenced transformants, control EP67, and Mock at 3 DPI (middle panel); probe B was used for hybridization. Loaded amounts of rRNA for each treatment are shown as a control (upper panel). Accumulation of siRNA on the silenced transformants and control EP67 and Mock (lower panel). Equal amounts of siRNA were loaded $(10 \mu \mathrm{g})$ for each treatment and blots were hybridized to probe $\mathrm{C}$. confirms these results. A single band of approximately 3,000 bp was present on the wild-type EP67, the product of the restriction between the KpnI site at 1,402 and a site outside the gene toward its $5^{\prime}$ end on the Cryphonectria genome. Southern analysis indicated that the silencing vector had integrated into the selected mutant's genomes (Fig. 3C) and that, in each case, the endogenous locus was not affected (Fig. 3C and D). The entire silencing hairpin unit should be detected at 2,100 bp by the $K p n I$ restriction digestion and represents the insertion of the silencing vector into the genome; such inserts were present in the mutants and absent from the EP67 control (Fig. 3C). The presence of unchanged 3,000- and 1,700-bp bands in both controls and mutants after KpnI or SacI digestion, respectively (Fig. 3C and D), shows that the wild-type Kex2 locus was unaffected and that the silencing vector did not undergo homologous recombination with the Kex 2 locus, in which case we would have seen these bands change size. Therefore, the decrease in Kex 2 activity was not due to gene knock-out but due to gene silencing. The differences in intensity of hybridization signals are due to unequal loading. For a description of probes and expected band sizes see Figure $3 \mathrm{~A}$ and $\mathrm{E}$.

Kex2 protein levels were analyzed in the selected silenced mutants at 1,2, and 3 days postinoculation (DPI) by Western blots using Kex 2 antibodies raised against bacterially expressed CpKex2 protein (Fig. 4A). Similar amounts of Kex2 protein were detected at all timepoints that were checked in the control strain, suggesting constitutive expression of Kex2, and a moderate reduction of protein levels could be observed in transformant Mut-P. No Kex 2 protein was detected in transformant Mut-G (Fig. 4A). The expression of CpKex 2 mRNA was examined by Northern blots. The selected silenced transformants lacked detectable amounts of the full-length CpKex 2 mRNA. The Mut-P (moderately silenced) strain showed accumulation of hairpin RNA and degraded transcripts whereas Mut-G showed more severe transcript product degradation (Fig. 4B). Full CpKex2 transcripts were always hard to detect, even on wild-type strains, and sometimes we were unable to detect them after 7 days of film exposure to the blots. This, we speculate, is due to constitutive low levels of expression, and the inability to detect the full transcripts in the mutants is due to the significant further reduction in transcript levels (60 to $70 \%$ ) bringing the samples beyond detection limits. We also carried out assays to detect the presence of $C p K e x 2$-specific siRNA in the silenced mutants. As expected, a large accumulation of siRNA was observed in Mut-G, showing a strong silencing effect. However, the moderately silenced Mut-P showed no significant siRNA accumulation compared with control EP67 and Mock (Fig. 4B, lowest panel). Similar results have been previously described for strong and moderately silenced $M$. oryze mutants (Kadotani et al. 2003). A full correlation of Kex2 protein levels, enzymatic activity, and relative transcript amounts of control EP67, Mock transformed, and silenced strains at 3 DPI can be seen in Figure 5A, B, and C, respectively. The EP67 and Mock controls show high levels of Kex2 protein (Fig. 5A), enzymatic activity (Fig. 5B), and relative RNA transcript levels (Fig. 5C) while Mut-P shows a moderate decrease in Kex2 protein levels and Kex2 activity and an approximately $60 \%$ reduction in RNA transcript levels. The strongly silenced strain Mut-G shows a significant decrease in Kex 2 activity and no Kex 2 protein could be detected on Western blots. Relative transcript levels were approximately $70 \%$ less than control strains. The fact that some enzymatic activity can be observed while no protein can be detected on Western blots in Mut-G strains can be explained by the loss of compartmentation caused by the detergent solubilization and subsequent exposure of the substrate to other, less specific proteases such as monobasic aspartyl proteases which can hydrolyze at dibasic cleavage sites (Jalving et al. 2000; Komano and Fuller 1995). 
The phenotype associated with the silenced strains on PDAmb plates only showed limited differences compared with that of the wild type. Growth rate of the two mutant strains at 3 and 7 DPI were not significantly reduced compared with the EP67 control (Fig. 6A); similar results were observed on dry weight analysis of cultures grown in liquid (not shown). Pycnospore production showed no difference between EP67 and Mut$\mathrm{P}$; however, there was a 10 -fold decrease in conidial numbers between EP67 and Mut-G (Table 1). Pycnidia formed on malt agar were found to be more numerous and smaller in size in Mut-P and even more so in Mut-G (Table 1). The asexual fruiting bodies of EP67, Mock controls, and the silenced mutants
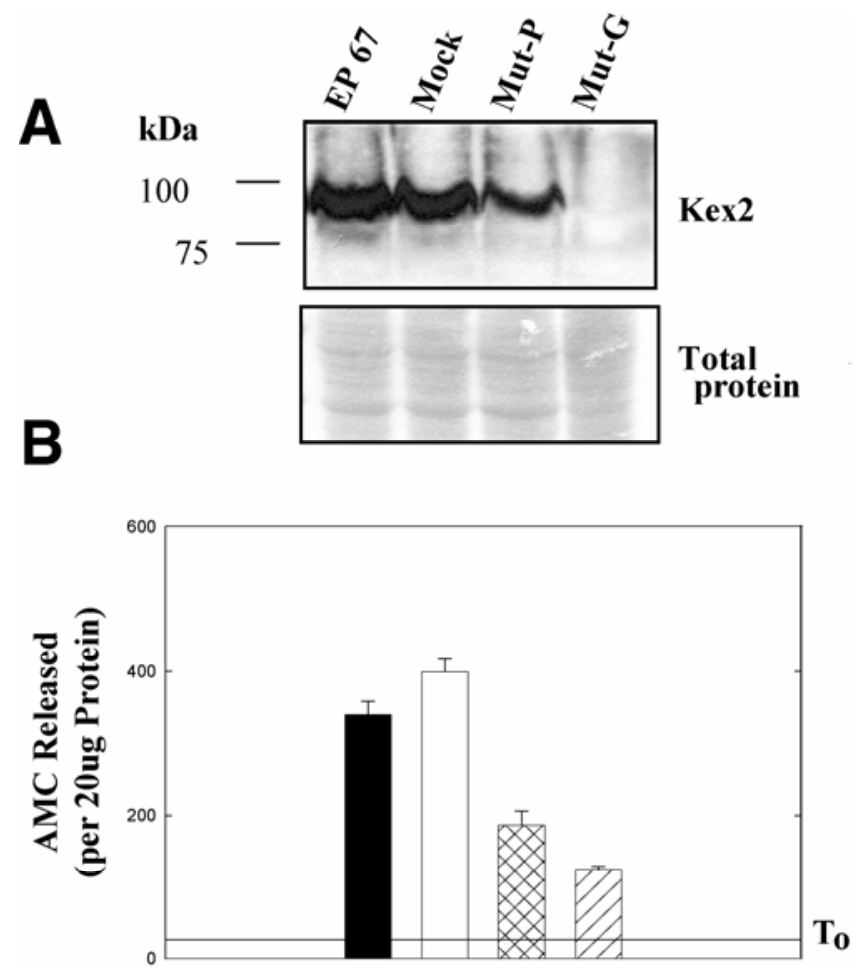

C

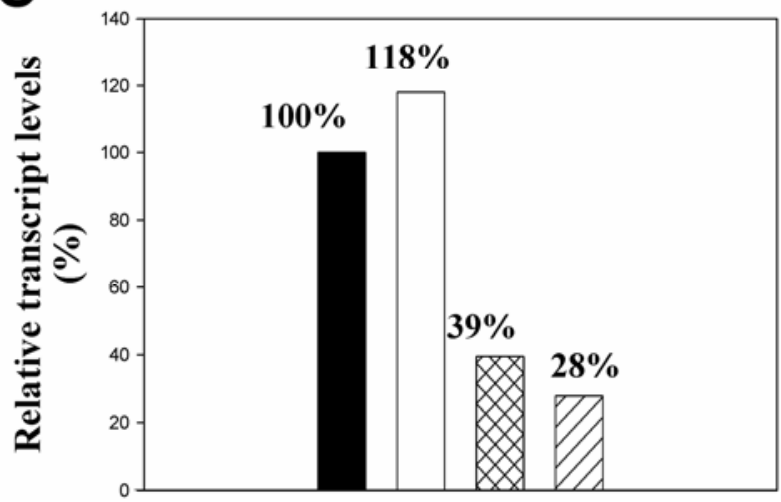

Fig. 5. Western blot analysis, Kex 2 activity, and real-time reverse-transcription polymerase chain reaction (RT-PCR) of controls and selected Kex2-silenced mutants, exhibiting varying degrees of Kex2 protein presence and activity. A, Western analysis. Lysates were prepared from control, virulent EP67, Mock, and Kex2-silenced strains Mut-P and Mut-G at 3 days postinoculation and run on an $8 \%$ sodium dodecyl sulfate polyacrylamide gel electrophoresis gel, blotted and probed with Kex2 antisera. Migration position of molecular weight markers is indicated on the left. $\mathbf{B}$, Kex 2 activity expressed as AMC released per $20 \mu \mathrm{g}$ of total protein. Control $\left(\mathrm{T}_{\mathrm{o}}\right)$ reactions were stopped before substrate addition. $\mathbf{C}$, Kex2 relative transcript accumulation in controls and silenced transformants, as measured by real-time RT-PCR. Three replicates were assayed for each data point for enzymatic assays and real time RT-PCR. were all able to colonize and erupt through the bark of autoclaved chestnut wood (data not shown). Thus, Kex2-silenced mutants were as effective at colonizing dead chestnut wood as were control strains. Differences were found in the ability of

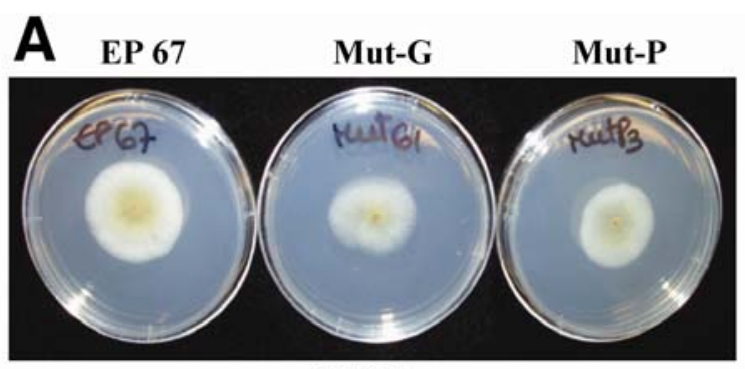

3-DPI

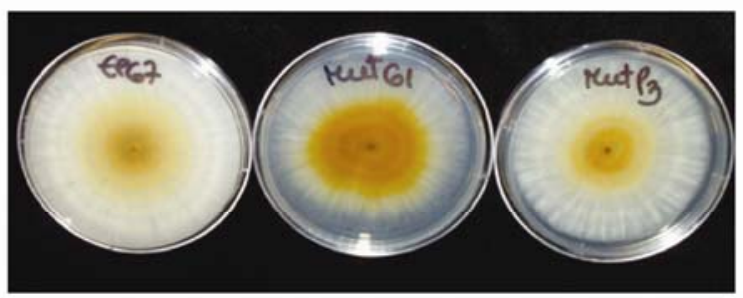

B

7 DPI

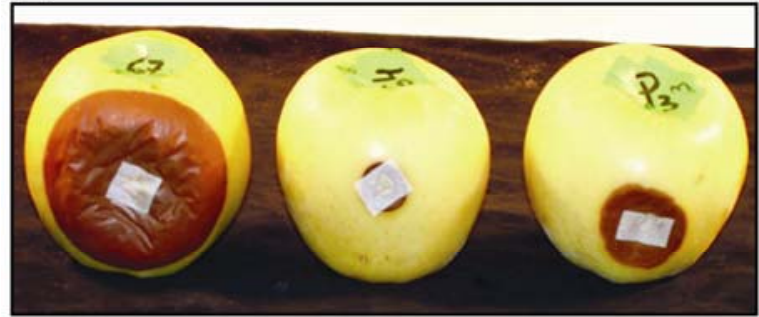

C

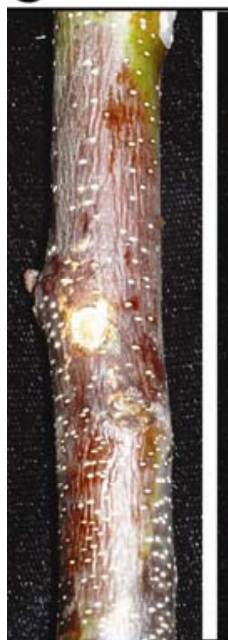

EP67

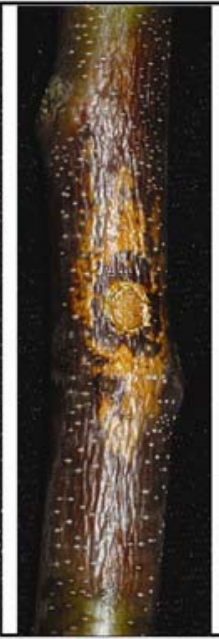

Mock

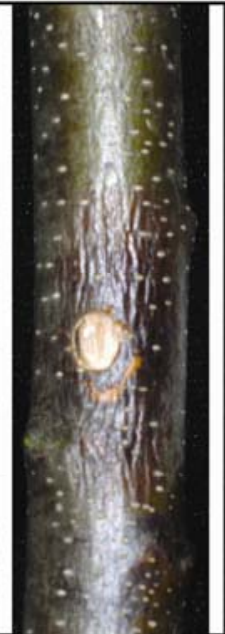

Mut-P

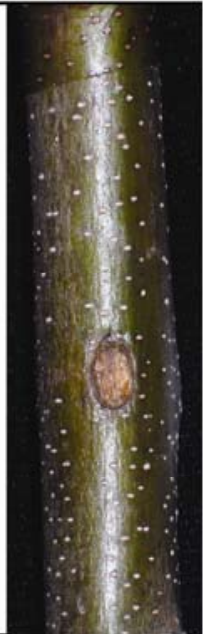

Mut-G
Fig. 6. Virulence assays and colony morphology of Kex2-silenced mutants. A, Colony morphology on potato dextrose agar with methionine and biotin (PDAmb) at 3 and 7 days postinoculation (DPI). B, Differences in virulence observed between isolates at 21 DPI. Virulence assays were performed on Golden Delicious apple fruit and measurements were made at 7,14 , and 21 DPI. Each isolate was used to inoculate three fruit, two isolates per fruit on opposite faces. Wild-type Cryphonectria parasitica, EP67, and uninoculated PDAmb Hyg plugs were used as positive and negative controls, respectively. C, Virulence assays performed on dormant chestnut tree stems. Pictures were taken at 14 DPI. From left to right: virulent strain EP67, Mock, Mut-P, and Mut-G strains. Three independent experiments were carried out; representative results are shown. 
the mutant strains to mate (Table 2) when compared with controls. Control mating crosses resulted in fertile perithecia within 1 month of fertilization $\left(\mathrm{EP} 67 \circ \times \mathrm{EP} 155{ }^{\lambda}\right.$ and EP155 $9 \times$ EP67 3 ). Perithecia could be observed in all crosses tested; however, perithecia were always barren when silenced mutants were used as male parent in the mating assay, indicating that Kex2 is required for male fertility. When used as females, Mut-P perithecia bore very few ascospores and Mut-G perithecia were always barren (Table 2).

\section{Lesion formation on apple.}

To determine whether $C p K e x 2$ silencing affects $C$. parasiticas virulence, Golden Delicious apple fruit were inoculated with 7-day-old mycelia from the EP67 control, isogenic silenced mutants, uninoculated PDAmb ${ }_{(\mathrm{Hyg})}$ plugs as negative controls, and pCPXHY1 plasmid fused to GFP as transformation control. The radius of infection lesions was measured at 7, 14, and $21 \mathrm{DPI}$ and then the mean lesion radius of each isolate calculated. The results are shown in Table 3 and Figure 6B. C. parasitica wild-type strain EP67 produces a dark-brown rot lesion. Very small lesions developed on the negative control fruit, consistent with wound stress. In general, silenced mutants produced smaller lesions than EP67. Whereas Mut-G isolates (with very low Kex2 activity) produced very small lesions, Mut-P isolates (with mild Kex 2 activity) produced lesions that were smaller than the EP67 control and bigger than those of Mut-G and negative control isolates. Mock controls were indistinguishable from virulent EP67 (Table 3). The silenced isolates show reduced virulence in apple and this reduced virulence correlates with their relative Kex 2 enzymatic activity.

\section{Canker formation on chestnut stems.}

Canker formation on dormant chestnut wood was also used to examine the virulence potential of the Kex2-silenced strains. Similar to our observations in the apple virulence assay, silenced transformants produced cankers that were significantly smaller than the wild type and Mock controls (Fig. 6C). Mut-P produced smaller cankers compared with controls; Mut-G mostly produced no cankers at all or very small cankers consistent with wound stress (Fig. 6C; Table 4). Thus, the degree of Kex2 silencing strongly correlates with attenuation of fungal virulence.

Table 1. Effect of silencing Kex2 gene on pycnidial number, pycnidial size, and pycnospore numbers ${ }^{\mathrm{z}}$

\begin{tabular}{lccc}
\hline Isolates & $\begin{array}{c}\text { Log pycnidial } \\
\text { no./cm }\end{array}$ & $\begin{array}{c}\text { Log pycnidial } \\
\text { diameter }(\boldsymbol{\mu m})\end{array}$ & $\begin{array}{c}\text { Log pycnospore no./ } \\
\text { petri dish } \\
(\mathbf{1 0 0}-\mathbf{m m} \text { diameter })\end{array}$ \\
\hline EP67 & $1.29 \mathrm{a}$ & $2.95 \mathrm{a}$ & $7.65 \mathrm{a}$ \\
Mut-P & $1.47 \mathrm{ab}$ & $2.51 \mathrm{~b}$ & $7.24 \mathrm{a}$ \\
Mut-G & $2.73 \mathrm{~b}$ & $2.12 \mathrm{c}$ & $6.0 \mathrm{~b}$ \\
\hline
\end{tabular}

${ }^{\mathrm{z}}$ All isolates were plated on $1.5 \%$ malt agar and assessed after a 3-week incubation period at $26^{\circ} \mathrm{C}$ with a photoperiod of $14 \mathrm{~h}$ of light and $10 \mathrm{~h}$ of darkness. Means were log-transformed to meet the assumption of homoscedasticity for analysis of variance. There were six replicates per isolate. Values within a column followed by the same letter are not significantly different according to Tukey's highly significant difference, $P<0.05$.

Table 2. Mating experiment results

\begin{tabular}{lccc}
\hline Female Q strain & Male $\delta$ strain & Plates with perithecia & Ascospores \\
\hline EP155 & EP67 & $5 / 6$ & + \\
EP155 & Mock & $6 / 6$ & + \\
EP155 & Mut-P & $3 / 6$ & - \\
EP155 & Mut-G & $3 / 6$ & - \\
EP67 & EP155 & $6 / 7$ & + \\
Mock & EP155 & $7 / 7$ & + \\
Mut-P & EP155 & $7 / 7$ & + \\
Mut-G & EP155 & $3 / 7$ & - \\
\hline
\end{tabular}

\section{DISCUSSION}

RNA silencing or post-transcriptional gene silencing is a wellconserved mechanism throughout a wide range of eukaryotes. It has been reported for plants (Napoli et al. 1990), animals (Fire 1999), and fungi (Romano and Macino 1992) and has emerged as a powerful tool for gene targeting and as an alternative method for the reduction of expression and analysis of lethal genes that cannot be studied using the gene disruption approach (Nakayashiki et al. 2005). The effectiveness of intron-containing hairpin constructs for RNA silencing was previously developed and reported for C. parasitica (Gullusci and Turina 2007; Segers et al. 2006) and compared well with the silencing efficiencies reported for $N$. crassa using a similarly designed silencing vector (Goldoni et al. 2004).

Kexin-like proteinases and mammalian furins are calciumdependent serine endopeptidases or proprotein convertases (PCs). Many secreted proteins are initially synthesized in a precursor or preproform and are later proteolytically converted into their mature active forms in part by this family of proteins. Mammalian PCs process neuropeptides, hormones, growth and differentiation factors, cell-surface receptors, extracellular metalloproteinases, adhesion molecules, bacterial toxins, diphtheria toxin, and viral coat proteins such as those from lethal Ebola viruses, HIV-1, and cytomegalovirus (Henrich et al. 2005; Khatib et al. 2002; Rockwell and Thorner 2004; Taylor et al. 2003; Thomas 2002). Due to their importance in pathogenicity, these proteins and their inhibitors have been the subject of extensive studies (Rockwell and Thorner 2004).

In yeast, Kex 2 has been shown to be necessary for the maturation of the $\alpha$-sex pheromone, a virus-encoded killer toxin

Table 3. Virulence on Golden Delicious apple fruit ${ }^{\mathrm{y}}$

\begin{tabular}{lccc}
\hline & \multicolumn{3}{c}{ Mean lesion radii $(\mathbf{m m})^{\mathbf{z}}$} \\
\cline { 2 - 4 } Isolates & $\mathbf{7 ~ D P I}$ & $\mathbf{1 4} \mathbf{~ D P I}$ & $\mathbf{2 1 ~ D P I}$ \\
\hline Mock & $7.76 \mathrm{a}$ & $22.05 \mathrm{a}$ & $48.0 \mathrm{a}$ \\
EP67 & $11.28 \mathrm{a}$ & $27.76 \mathrm{a}$ & $49.9 \mathrm{a}$ \\
Mut-P & $6.14 \mathrm{ab}$ & $12.06 \mathrm{~b}$ & $25.9 \mathrm{~b}$ \\
Mut-G & $3.30 \mathrm{~b}$ & $3.80 \mathrm{c}$ & $6.5 \mathrm{c}$ \\
Control (-) & $1.58 \mathrm{c}$ & $3.30 \mathrm{c}$ & $3.8 \mathrm{~d}$ \\
\hline
\end{tabular}

${ }^{y}$ Golden Delicious apple fruit were inoculated with 7-day-old mycelia (grown on potato dextrose agar with methionine and biotin [PDAmb] or PDAmb Hyg) to determine differences in virulence between Kex2-silenced strains and controls. Mock, wild-type Cryphonectria parasitica transformed with pCPXHY1 plasmid fused to green fluorescent protein; EP67, virulent wild-type C. parasitica; Mut-P and Mut-G, Kex2-silenced strains P and $G$, respectively (different extent of silencing); Control (-), negative control. Apple fruit were wounded and inoculated with sterile PDAmb.

${ }^{\mathrm{z}}$ The radius of the original wound was not subtracted from final measurements. Values were transformed by $\log _{10}$ for analysis and separation of means for analysis of variance, but actual values are reported. Values within a column followed by the same letter are not significantly different according to Tukey's highly significant difference, $P<0.01$; DPI = days postinoculation.

Table 4. Mean canker areas induced on American chestnut stems by virulent Cryphonectria parasitica strain EP67, Mock, and Kex2-silenced strains P and G (Mut-P and Mut-G, respectively)

\begin{tabular}{lcr}
\hline Isolates & Mean canker area $\left(\mathbf{m m}^{\mathbf{2}}\right)^{\mathbf{y}}$ & $\mathbf{\pm} \mathbf{S D}^{\mathbf{z}}$ \\
\hline Mock & 6,550 & 836 \\
EP67 & 6,767 & 941 \\
Mut-P & 3,727 & 1,312 \\
Mut-G & 183 & 288 \\
\hline
\end{tabular}

${ }^{y}$ Mean canker areas were determined 14 days after inoculation on five replicates. Canker area was calculated using the formula for an ellipse. The area of the original wound was not subtracted from final measurements.

${ }^{\mathrm{z}} \mathrm{SD}=$ standard deviation. 
(Julius et al. 1984), and various cell-wall components (Brickner and Fuller 1997; Goller et al. 1998; Iguchi et al. 1997). In this respect, the $C$. parasitica's Kex 2 protein may have a similar effect on the $\alpha$-pheromone of $C$. parasitica. In fact, fertility of $C$. parasitica was severely affected by Kex2 silencing and, even though the silenced strains were able to produce perithecia, there were always fewer in the severely silenced crosses and the perithecia were usually barren. This phenotype indicates that Kex2 silencing affects both male and female fertility. A previous deletion of the $\alpha$-sex pheromone $M f 1-1$ precursor gene in $C$. parasitica was shown to cause male sterility. When this mutant strain was used in a sexual cross, it produced no perithecia when used as a male; however, when used as a female parent, they were able to produce fertile perithecia in normal amounts (Turina et al. 2003).

The Mfl-1 pheromone precursor gene encodes for a decapeptide organized similarly to that of the yeast $\alpha$-pheromone with processing signals for recognition by a Kex2-like endoprotease in the pheromone activation and secretion process. Thus, fewer perithecia observed in the crosses using the Kex2silenced strains as males probably indicates an effect on male fertility through disruption of the $M f 1-1$ pheromone processing into its active form. However, the reduction of perithecia observed when a severely silenced strain was used as a female in crosses suggests that Kex 2 silencing affects fertility not only by disruption of processing of the Mfl-1 pheromone but also in some other as-yet-unknown way. In this respect, the Kex2 gene in $S$. cerevisiae has been shown to be required not only for normal mating by $\alpha$-strains but also for meiotic sporulation in all strains (Leibowitz and Wickner 1976). It is possible, then, that the barren perithecia observed in Kex2 silencing of $C$. parasitica is a result of a Kex 2 effect on meiosis, as shown for yeast; however, other possibilities cannot be ruled out.

When $C$. parasitica is infected with CHV1 it is female sterile but male fertility is normal, except that many fewer conidia are produced by infected strains (Anagnostakis 1984). Thus, there are differences between CHV1 infection and Kex2 silencing on phenotypic expression in $C$. parasitica although both adversely affect $C$. parasitica's mating phenotype. Interestingly, the virus and Kex2 silencing each reduce the number of conidia produced by the fungus but the silenced strains produced more pycnidia of smaller size than the wild-type and viral-infected strains.

The silencing of Kex2 suggests that this enzyme is an essential factor for virulence expression of $C$. parasitica. The silencing of this enzyme did not have a significant effect on fungal growth; therefore, the reduced virulence of Kex2-silenced strains is not due to generalized fungal debilitation. Most likely, Kex2 is involved in processing proteins necessary for virulence expression. In Candida albicans, it has been demonstrated that kexin activity is required for full virulence. Deletion of the Kex2 gene in C. albicans negatively affects the secretion of active aspartyl proteinase and the formation of hyphae, two mayor virulence factors (Newport and Agabian 1997; Newport et al. 2003).

Kex2-silenced mutants of Cryphonectria parasitica formed small lesions when the fungus was inoculated on apple and canker formation was reduced on dormant chestnut wood, which are the standard virulence assays for $C$. parasitica (Elliston 1985; Fulbright 1984). These could result from the mutant's reduced ability to advance colony growth in either tissue. Although the $C p K e x 2$-silenced mutants showed reduced ability to expand growth on apple fruit or dormant chestnut wood, they did effectively penetrate autoclaved chestnut wood and form stromata containing fruiting bodies within the wood (not shown).

The cell-surface hydrophobin cryparin is one of the fungal proteins that are secreted in lower amounts by CHV1-infected strains than noninfected strains. This protein, like $M f 1-1$, is transcribed as a preproprotein and has the appropriate amino acid sequence for Kex2 processing. Cryparin was shown to be required for stromal pustule eruption through the bark of autoclaved chestnut wood (Kazmierczak et al. 2005); therefore, the normal eruption of these asexual fruiting bodies by Kex2-silenced strains was unexpected. It was assumed that without normal Kex2 processing, cryparin would not have been secreted or its properties as a hydrophobin would have been disrupted enough to prevent its incorporation into the walls of stromal pustules. To determine whether cryparin was processed prior to secretion, we harvested cryparin from liquid cultures of the Kex2 Mut-G strain and determined its $\mathrm{N}$-terminal sequence. We found that approximately $50 \%$ of the secreted cryparin was properly processed, suggesting that normal processing was perturbed but not eliminated in this Kex2-silenced mutant strain (not shown). Low levels of Kex2 activity in the silenced strains may have remained, or there may be inefficient alternative processing mechanisms for the maturation of cryparin in the absence of Kex2. Whatever the mechanism, sufficient cryparin was processed in the Kex2-silenced strains to allow normal eruption of the stromal pustules through bark.

Fungi such as $S$. cerevisiae, Yarrowia lipolytica (Komano and Fuller 1995; Richard et al. 2001), or A. niger (Jalving et al. 2000) and A. oryzae (Mizutani et al. 2004) showed severe growth defects in response to mutation of Kex2. In S. cerevisiae, in addition to sexual sterility, Kex2-null mutants were temperature sensitive in growth and exhibited defects in spore formation (Leibowitz and Wickner 1976). Deletion of kexins of $Y$. lipolytica and Candida albicans resulted in lack of hyphal growth, indicating an involvement of Kex2 in dimorphisim (Newport and Agabian 1997; Richard et al. 2001). Disruption of the A. niger KexB gene caused various morphological alterations such as shorter and multibranched hyphae (Jalving et al. 2000) while $K \operatorname{exB}$ disruption in $A$. oryzae led to shrunken colonies that were thicker and multibranched and produced neither conidiophores nor conidia (Mizutani et al. 2004). In C. glabrata, Kex2 was shown to be essential for cell wall integrity (Bader et al. 2001). Comparison of Cryphonectria parasiticas Kex2 silencing phenotypes with those observed in fungi that had been knocked out are complicated by the nature of the differences of the methods themselves. The lack of severe effects of Kex2 silencing in C. parasitica on colony morphology or growth could be attributed to leaky silencing. However, it may also indicate that Kex2 is not an essential factor in vegetative growth. Processing by Kex 2 may be limited to those proteins involved exclusively in developmental processes such as sporulation, mating, and virulence, phenotypical features that were drastically affected by the silencing of Kex2 in C. parasitica. There may, in addition, be alternate processing or enzyme concentration effects, as suggested by partial processing of the cryparin protein that could be responsible for these Kex 2 phenotypic differences between vegetative and developmental processes. The fact that we were unable to obtain Kex2 deletions might imply that Kex 2 is essential for early development or that the deletion phenotype was lethal.

The overall effects of Kex 2 mutation and infection by CHV1 on $C$. parasitica are similar but there are differences between them (i.e., on numbers of asexual sporulation bodies and the specific way sexual crossing is affected). It would be premature to conclude that CHV1's effect on $C$. parasitica is due solely to disruption of Kex 2 processing and secretion. CHV1 utilizes TGN vesicles for replication and these vesicles are the only host membrane known to co-purify with virus RNA and proteins (Jacob-Wilk et al. 2006). The p29 viral protein specifically targets these TGN vesicles for integration into the membrane. This vesicle fraction, which supports virus 
replication, contains virus RNA and virus-specific proteins such as viral RNA polymerase and helicase, plus p29 cofractionate with the peak of Kex 2 activity (Jacob-Wilk et al. 2006). Thus, there is a likely physical connection between the virus within the host cell and host vesicles involved in Kex 2 processing and secretion. The similarity in phenotypes between Kex 2 silencing and CHV1 infection together with the co-purification of TGN vesicles supporting virus replication and Kex2 processing suggests that some common mechanisms might be involved.

Pathogenicity is dependent on cell-to-cell communication and polarized hyphal growth (Gow 1995; Steinberg 2007). Some pathogenic fungi require exoenzymes for attachment and penetration of host tissues; therefore, these secreted molecules are virulence factors (Steinberg 2007; Tucker and Talbot 2001). Thus, it is possible that the low-virulence phenotype associated with CHV1 infection and Kex2 silencing is the result of disruption of protein processing and secretion. It has been observed that TGN vesicles accumulate in CHV1-infected strains (Hansen et al. 1985; Jacob-Wilk et al. 2006; Newhouse et al. 1983, 1990). This may be a symptom of disruption of normal vesicle trafficking, perhaps as a result of virus targeting of these vesicles for replication. These apparent effects on vesicle trafficking may result in less efficient secretion of proteins important in developmental processes such as sporulation and virulence. Similarly, Kex2 silencing may affect virulence by perturbing processing and secretion of proteins important in development. The most important implication of these studies is that, in both Kex2 silencing and CHV1 infection, only development is affected; vegetative growth remains normal and, thus, there may be a separation of secretion pathways in this fungus between vegetative growth and development, with Kex2 being exclusive to development. This hypothesis is testable and is the basis of current research in our laboratory.

In this study, we showed that silencing of the Kex2 gene, which encodes a protease involved in protein maturation, results in reduced fungal virulence. This effect was accompanied by a significant reduction in sporulation and mating while no other significant phenotypic changes could be observed, suggesting an involvement of Kex 2 in developmentally regulated processes. Due to its cytosolic localization, it is unlikely that the Kex 2 protein itself is responsible for the reduced virulence observed. A more likely explanation is that Kex 2 is required for the processing or activation of extracellular proteins involved in developmental processes such as virulence expression.

\section{MATERIALS AND METHODS}

\section{Growth of cultures.}

EP complete liquid medium (1 liter) (Puhalla and Anagnostakis 1971) in a Fernbach flask was inoculated using cultures that were previously grown for 7 days on PDAmb petri plates. To inoculate liquid cultures, the agar cultures were homogenized for $1 \mathrm{~min}$ in EP complete at full speed in a Waring Blender (New Hartford, CT, U.S.A.) before being added to the liquid medium. The cultures were grown on an orbital shaker at room temperature for 3 days under ambient light. Mycelia were harvested by filtration and immediately processed or frozen and stored at $-80^{\circ} \mathrm{C}$. Growth rates of control and silenced strains were assessed in two independent experiments; three replicates per treatment were measured in each experiment. In one experiment, each replicate was inoculated and grown on 1 liter of EP complete as described above. Liquid cultures were harvested, frozen, and lyophilized at 3 DPI for total dry weight measurements. In the second experiment, 200-ml flasks filled with $50 \mathrm{ml}$ of EP complete were inoculated with a one-quarter plate of inoculum and cultures were grown as previously described; three replicates per treatment per timepoint were harvested at 1, 2, and 3 DPI, frozen, and lyophilized for dry weight measurements.

\section{Pycnidium number and size assessment and analyses of asexual sporulation.}

Isolates analyzed for pycnidial numbers and size were plated on $1.5 \%$ malt extract agar (MEA). Media ( $25 \mathrm{ml} /$ plate) were inoculated with a 5-mm-diameter inoculum removed from the leading edge of a 7-day-old culture grown on PDAmb. The plates were grown at $25^{\circ} \mathrm{C}$ with a photoperiod of $14 \mathrm{~h}$ of light and $10 \mathrm{~h}$ of darkness. Three replicates of each isolate per treatment were assessed at 3 weeks postinoculation in two independent experiments. Pycnidial numbers were assessed with the aid of a MZFLIII Leica dissecting microscope (Heerbrugg, Switzerland). Images were captured at $\times 8$ magnification from within a circular area measuring $2 \mathrm{~cm}$ in radius from the point of inoculation using a digital camera from $\mathrm{Di}$ agnostic Instruments (model 2.2.1; Diagnostic Instruments, Sterling Heights, MI U.S.A.). An area of $164.3 \mathrm{~mm}^{2}$ near the point of inoculation was captured. Spatial calibration of pixels was done with a stage micrometer. Three such areas were captured and the pycnidia contained within these areas counted.

Size measurements of individual pycnidia within these same areas were made across the widest area in millimeters of each individual pycnidium. Sizes were converted to microns. For both experiments, a minimum of three replicates was included for each treatment.

Values for pycnidial numbers and sizes were transformed by $\log _{10}$ for analysis and separation of means by analysis of variance.

Asexual sporulation was assessed after growth of strains on $1.5 \%$ MEA for 3 weeks under the conditions described above. Plates were flooded with $10 \mathrm{ml}$ of water and the pycnidia disrupted with a glass rod. Plates were incubated at room temperature for $5 \mathrm{~min}$ and the resulting fluid collected and passed through a 5-ml pipette tip plugged with cotton to remove mycelia debris. The spore concentration was determined by counting with a hematocytometer. The data were analyzed as described above.

\section{Silencing vector construction and generation of mutant strains.}

A silencing vector was constructed using fungal vector pCPXHY1, a derivative of pAXHY2 created by replacing ORFA with several unique cloning sites (Choi and Nuss 1992a and $\mathrm{b}$ ). The $C$. parasitica glyceraldehyde-3-phosphate dehydrogenase $(g p d-1)$ promoter and the $g p d-1$ terminator were fused upstream and downstream to these unique cloning sites. The vector also contains the hygromycin B phosphotransferase gene as a selectable marker flanked by the $\operatorname{trp} C$ promoter and terminator of A. nidulans (Cullen et al. 1987).

Genomic DNA from $C$. parasitica was amplified by polymerase chain reaction (PCR) to obtain two independent Kex2 PCR products. The first 900-bp fragment was amplified using primers sil5 and sil3A containing KpnI and BamHI restriction sites respectively. The second 1,214-bp fragment was obtained using primers sil5 and sil3B containing KpnI and BamHI restriction sites, respectively. Both fragments were cloned independently in PCR vector pGEM-T Easy (Promega Corp., Madison, WI, U.S.A.). PCR fragment B was released using BamHI and SpeI and ligated to pGEM-T containing fragment A that was previously cut with BamHI, SpeI, creating an inverted repeat containing a 314-bp spacer created artificially by the noncomplementary DNA sequenced amplified in the Kex2B fragment (900 to $1,214 \mathrm{bp}$ ). The inverted repeat was then cloned into pCPXHY1 using KpnI. Primer sequences 
were as follows: sil5, 5'GGTACCAAGCTTCTTCGAAAGAC AGCGCC3'; sil3A, 5'GGATCCAGCGCGTGCCGTGCCTGT CGT3'; and sil3B, 5'GGATCCGCAGTTGTCATCGCTGGCA GC3'. A previously constructed vector featuring pCPXHYI fused to GFP (Jacob-Wilk et al. 2006) was used as a negative mock control in our experiments (termed Mock).

C. parasitica spheroplasts from strain EP67 (Zhang et al. 1998) were obtained and transformed as previously described (Churchill et al. 1990). Transformants growing on hygromycin were analyzed for Kex 2 expression by enzymatic assay and by Western and Southern blot analyses. All transformants identified for further studies were shown to be mitotically stable and were single-spored to assure that cultures were derived from a single nucleus.

\section{RNA extraction and Northern blot analysis.}

To extract RNA from cultures, $700 \mu$ of RNA extraction buffer and $700 \mu \mathrm{l}$ of phenol/chloroform mix (Ambion, Austin, TX, U.S.A.) were added to $15 \mathrm{mg}$ of lyophilized mycelia in 2$\mathrm{ml}$ tubes containing $0.5-\mathrm{mm}$ glass beads. The cells were broken open using a bead beater (BioSpec, Bartlesville, OK, U.S.A.) for $2 \times 30 \mathrm{~s}$. The tubes were microfuged for $5 \mathrm{~min}$ at maximum speed and the supernatant extracted twice with phenol/chloroform. RNA was precipitated using $10 \mathrm{M} \mathrm{LiCl}$ to make a final concentration of $2 \mathrm{M}$. The pellets were resuspended in $50 \mu \mathrm{l}$ of diethylpyrocarbonate (DEPC)-treated water. The RNA was denatured, separated, and transferred onto membranes using the glyoxal-phosphate electrophoresis method as previously described (Sambrook et al. 1989). Northern blot analysis was done as previously described (Zhang et al. 1998).

\section{Quantitative reverse-transcriptase-PCR.}

For quantitative reverse-transcriptase PCR, $10 \mu \mathrm{l}$ of total RNA was treated with RNase free DNase (New England Biolabs, Beverly, MA, U.S.A.), for $30 \mathrm{~min}$ at $37^{\circ} \mathrm{C}$. The reaction was stopped by adding EDTA to a final concentration of 1.25 $\mathrm{mM}$ and heating to $65^{\circ} \mathrm{C}$ for $10 \mathrm{~min}$. This reaction $(5 \mu \mathrm{l})$ was preincubated with $1.5 \mu \mathrm{l}$ of Random primer $(3 \mu \mathrm{g} / \mu \mathrm{l})$ (Invitrogen, Carlsbad, CA, U.S.A.) and $3.5 \mu$ of DEPC $\mathrm{H}_{2} \mathrm{O}$ and transferred to a new microfuge tube for reverse transcription at $42^{\circ} \mathrm{C}$ for $60 \mathrm{~min}$ in a final volume of $25 \mu \mathrm{l}$. Reverse transcription reaction conditions were as follows: $5 \mu \mathrm{l}$ of $5 \times$ reaction buffer (Promega Corp.), $2 \mu$ of dNTPs $(10 \mathrm{mM})$ stock, $0.5 \mu \mathrm{l}$ of RNAse inhibitor, stock at $20 \mathrm{U} / \mu \mathrm{l}$ (Applied Biosystems, Foster City, CA, U.S.A.), $1 \mu \mathrm{l}$ of M-MLV Reverse transcriptase (Promega Corp.), and $6.5 \mu \mathrm{l}$ of DEPC $\mathrm{H}_{2} \mathrm{O}$. The cDNA was diluted in a 1:5 ratio and $5 \mu$ was subjected to quantitative real-time PCR with TaqMan master mix reagents (Applied Biosystems) in a total volume of $25 \mu \mathrm{l}$ with primer set $4^{\text {th }}$ setkex forward: GGTCATCAGCCATCT CTCGG and $4^{\text {th }}$ setkex reverse: GTGCTCGTTCACCTTGG TGTC designed by using Primer Express software (Applied Biosystems) and performed using a 7500 RT-PCR system from Applied Biosystems. These primers were located at bases 1,841 and 2,064 on the genomic sequence, respectively, and the predicted product was expected to be of 147 bp (after the intron sequence subtraction of 76 bases). The abundance of transcript in each sample was calculated using a relative standard curve and normalized to $18 \mathrm{~S}$ rRNA transcript amounts in each sample as an endogenous control using the following primers: 18S rRNA forward, 5'ATAAC AGGTCTGTGATGCCCTTAGA3' and 18S rRNA reverse, 5'CTCGCTGGCTCTGTCAGTGTAG3'. Optimal primer concentrations were determined in each case as $250 \mathrm{nM}$ for both the forward and reverse Kex2 gene-specific primers and as $100 \mathrm{nM}$ for the $18 \mathrm{~S}$ rRNA gene-specific primers.

\section{DNA extraction and Southern blot analysis.}

Fungal genomic DNA was extracted as described previously (Turina et al. 2003). Southern blot analysis was performed as described (Sambrook et al. 1989). Genomic DNA was digested with appropriate restriction enzymes and transferred to Hybond $\mathrm{N}+$ (Amersham Biosciences, Piscataway, NJ, U.S.A.) after separation on a $1 \times$ Tris-acetate-EDTA $0.7 \%$ agarose gel.

\section{Kex2 assay and Western blots.}

Kex 2 protein was solubilized from $50 \mathrm{mg}$ of lyophilized mycelia by resuspending pellets in Kex 2 extraction buffer: $50 \mathrm{mM}$ sodium HEPES (pH 7.6), $1 \mathrm{mM}$ EDTA, $50 \mathrm{mM} \mathrm{NaCl}, 2 \%$ sodium deoxycholate, and $20 \%$ glycerol, with $0.5-\mathrm{mm}$ glass beads. After cell disruption, lysates were centrifuged and the resulting supernatant was stored at $-20^{\circ} \mathrm{C}$ until it was assayed for activity. The reaction mixture $(200 \mu \mathrm{l})$ contained $200 \mathrm{mM}$ sodium HEPES ( $\mathrm{pH} 7$ ), $1.5 \mathrm{mM} \mathrm{CaCl} 2,0.1 \mathrm{mM} \mathrm{L-1-tosyla-}$ mido-2-phenylethyl-CK (TPCK), and $100 \mu \mathrm{M}$ N-t-BOC-GLNARG-ARG 7-amido-4-methylcoumarine (b-QRR-MCA) from Sigma-Aldrich (St. Louis) as substrate. After substrate addition, reaction mixtures were incubated at $37^{\circ} \mathrm{C}$ for $30 \mathrm{~min}$. Control reactions were stopped before substrate addition (termed $\mathrm{T}_{\mathrm{o}}$ ). Reactions were terminated by addition of $1.6 \mathrm{ml}$ of $125 \mathrm{mM} \mathrm{ZnSO}_{4}$ and $0.2 \mathrm{ml}$ of saturated $\mathrm{Ba}(\mathrm{OH})_{2}$. The precipitate was removed by centrifugation for $5 \mathrm{~min}$ at $20,000 \times \mathrm{g}$ in a microcentrifuge, and the amount of 7-amino-4-methylcoumarin (AMC) liberated was determined fluorimetrically at $\lambda_{\mathrm{ex}}=$ $370 \mathrm{~nm} ; \lambda_{\text {em }}=440 \mathrm{~nm}$ (Jacob-Wilk et al. 2006; Jalving et al. 2000). All enzymatic reactions were assayed in three replicates.

Proteins were separated by sodium dodecyl sulfate (SDS) polyacrylamide gel electrophoresis using either 12 or 4-20\% gradient acrylamide gels as required and blotted onto nitrocellulose membranes. Western blot detection by Chemiluminescent ECL with SuperSignal West Pico substrate from Pierce (Rockford, IL, U.S.A.) was carried out according to the manufacturer's recommendations. Kex2 rabbit polyclonal antibody was self prepared as previously described (Jacob-Wilk et al. 2006) and used in a 1:8,000 dilution in PBS, 0.3\% Tween-20 and $7 \%$ milk. Secondary anti-rabbit-HRP conjugate was purchased from Sigma-Aldrich and used at 1:5,000 dilution in the same buffer.

\section{Isolation and detection of siRNA.}

Small-RNA purification was performed exactly as described by Segers and associates (2006) using Trizol reagent (Invitrogen). The low molecular weight RNAs were quantified on a NanoDrop ND-1000 spectrophotometer from NanoDrop Technologies, Inc. (Wilmington, DE, U.S.A.), heated to $95^{\circ} \mathrm{C}$ for 5 minutes in Novex Tris-borate-EDTA (TBE)-urea sample buffer (Invitrogen), and separated on a $15 \%$ polyacrylamide TBE (89 $\mathrm{mM}$ Tris, $89 \mathrm{mM}$ boric acid, and $2 \mathrm{mM}$ EDTA)-urea gel from Invitrogen. Along with the samples, a microRNA marker from New England Biolabs (Beverly, MA, U.S.A.) was loaded. The nucleic acids were electroblotted onto Hybond-N+ (Amersham Biosciences) in $0.5 \times \mathrm{TBE}$, soaked on chromatography paper for $30 \mathrm{~min}$ on $20 \times \mathrm{SSC}(1 \times \mathrm{SSC}$ is $0.15 \mathrm{M} \mathrm{NaCl}, 0.015 \mathrm{M}$ sodium citrate), and cross-linked by UV radiation. Hybridizations were carried out overnight at $40^{\circ} \mathrm{C}$ using $2 \times \mathrm{SSC}, 7 \%$ SDS, $5 \times$ Denhardt's solution, and salmon sperm at $100 \mu \mathrm{g} / \mathrm{ml}$ as prehybridization and hybridization solutions and a ${ }^{32} \mathrm{P}-$ labeled Kex2 probe. A 323-bp Kex2 probe was prepared by cutting silencing vector with restriction enzymes SmaI and $\mathrm{SacI}$ as schematically shown in Figure $3 \mathrm{E}$ and random primed labeling using a random primed labeling kit from Roche (Indianapolis, IN, U.S.A.) according to the manufacturer's instructions. After hybridization, blots were washed twice for $15 \mathrm{~min}$ with $2 \times \mathrm{SSC}, 0.2 \% \mathrm{SDS}$ at $40^{\circ} \mathrm{C}$. 


\section{Protein determination.}

Protein concentrations were determined with a BCA reagent kit (Pierce). Due to compatibility issues with Kex2 extraction buffer a Compat-Able Protein Assay Preparation Reagent Set (Pierce) was used prior to protein determination for Kex 2 assays. All procedures were carried out according to the manufacturer's recommendations.

\section{Pathogenicity tests.}

American chestnut (Castanea dentata) and European chestnut (Castanea sativa) dormant wood was used to determine pathogenicity of CpKex2-silenced mutants. Intact chestnut branches, approximately $40 \mathrm{~cm}$ long and $2.5 \mathrm{~cm}$ in diameter, were washed and their cut ends sealed with paraffin wax. Wounds were made by removing a plug $(5 \mathrm{~mm}$ in diameter) of bark to the depth of the cambium. Mycelia were placed into the wound with a flamed spatula and covered with tape to prevent desiccation. Each strain was inoculated along one piece of wood, approximately $8 \mathrm{~cm}$ apart and on the opposite side of the branch, and this inoculation pattern was replicated five times along different chestnut branches. Canker length and width were measured at 14 DPI and canker area was calculated by using the formula for an ellipse (Rigling et al. 1989).

Pathogenicity was measured concurrently in Golden Delicious apple fruit as previously described (Elliston 1985). Firm, mature apple fruit were washed with water and soaked for 3 min in $10 \%$ Chlorox solution, rinsed, and dried. A small shallow plug was removed from each apple at two opposite sides and inoculated with fungal plugs cut from the growing edge of 7-day-old culture plates. One fungal plug was inserted face down in each case and the inoculation point was sealed with masking tape. Four apple fruit per treatment were used. Fruit were incubated in a moist chamber at room temperature for 3 weeks. Measurements of radial growth of the fungal isolates were taken at 7,14 , and 21 DPI.

\section{Mating experiments.}

Mating experiments were carried out according to Anagnostakis (1979), with minor modifications (Turina et al. 2003). Stem cuttings from American chestnut trees that were less than $4 \mathrm{~cm}$ but greater than $5 \mathrm{~mm}$ in diameter were radially cut short enough to fit in a petri dish. Stem pieces were autoclaved and placed on $1 \%$ water agar plates containing biotin and methionine. Plates were inoculated with mycelial plugs from the female parent strain and grown for 3 weeks before conidia from the opposite mating type were used as male parents to fertilize the already established strain. Conidia were incubated in the plates for an hour and then excess liquid was poured from plates. The presence of perithecia was scored 1 and 2 months after fertilization. Perithecia were isolated and dissected for the observation of ascospores.

\section{ACKNOWLEDGMENTS}

We thank L. Kong for excellent technical assistance; L. Epstein for her help and advice regarding the statistical analysis of virulence in apple, pycnidial production, pycnidial size. and sporulation; and B. Falk and J. Lindbo for their helpful advice on the production, separation, and hybridization of siRNAs.

\section{LITERATURE CITED}

Anagnostakis, S. L. 1979. Sexual reproduction of Endothia parasitica in the laboratory. Mycologia 71:213-215.

Anagnostakis, S. L. 1984. Nuclear gene mutations in Endothia (Cryphonectria) parasitica that affect morphology and virulence. Genetics 74:561-565.

Bader, O., Schaller, M., Klein, S., Kukula, J., Haack, K., Mühlschlegel, F.,
Korting, H. C., Schäfer, W., and Hube, B. 2001. The Kex2 gene of Candida glabrata is required for cell surface integrity. Mol. Microbiol. 41:1431-1444.

Basco, R. D., Cueva, R., Andaluz, E., and Larriba, G. 1996. In vivo processing of the precursor of the major exoglucanase by KEX2 endoprotease in the Saccharomyces cerevisiae secretory pathway. Biochim. Biophys. Acta 1310:110-118.

Brickner, J. H., and Fuller, R. S. 1997. SOI1 encodes a novel, conserved protein that promotes TGN-endosomal cycling of Kex2p and other membrane proteins by modulating the function of two TGN localization signals. J. Cell Biol. 139:23-36.

Choi, G. H., and Nuss, D. L. 1992a. Hypovirulence of chestnut blight fungus conferred by an infectious viral cDNA Science 257:800-803.

Choi, G. H., and Nuss, D. L. 1992b. A viral gene confers hypovirulenceassociated traits to the chestnut blight fungus. EMBO (Eur. Mol. Biol. Organ.) J. 11:473-477.

Choi, G. H., Larson, T. G., and Nuss, D. L. 1992. Molecular analysis of the laccase gene from the chestnut blight fungus and selective suppression of its expression in an isogenic hypovirulent strain. Mol. Plant-Microbe Interact. 5:119-128.

Churchill, A. C. L., Ciuffetti, L. M., Hansen, D. R., Van Etten, H. D., and Van Alfen, N. K. 1990. Transformation of the fungal pathogen Cryphonectria parasitica with a variety of heterologous plasmids. Curr. Genet. 17:25-31.

Cullen, D., Leong, S. A., Wilson, L. J., and Henner, D. J. 1987. Transformation of Aspergillus nidulans with the hygromycin-resistance gene, hph. Gene 57:21-26.

Elliston, J. E. 1985. Characteristics of dsRNA-free and dsRNA-containing strains of Endothia parasitica in relation to hypovirulence. Phytopathology 75:151-158.

Fahima, T., Kazmierczak, P., Hansen, D. R., Pfeiffer, P., and Van Alfen, N. K. 1993. Membrane-associated replication of an unencapsidated double-strand RNA of the fungus, Cryphonectria parasitica. Virology 195:81-89.

Fire, A. 1999. RNA-triggered gene silencing. Trends Genet. 15:358-363.

Fulbright, D. W. 1984. Effect of eliminating dsRNA in hypovirulent Endothia parasitica. Phytopathology 74:722-724.

Goldoni, M., Azzalin, G., Macino, G., and Cogoni, C. 2004. Efficient gene silencing by expression of a double-stranded RNA in Neurospora Crassa. Fungal Genet. Biol. 41:1016-1024.

Goller, S. P., Schoisswohl, D., Baron, M., Parriche, M., and Kubicek, C. P. 1998. Role of endoproteolytic dibasic proprotein processing in maturation of secretory proteins in Trichoderma reesei Appl. Environ. Microbiol. 64:3202-3208.

Gow, N. A. R. 1995. The Growing Fungus. Chapman \& Hall, London.

Gullusci, M., and Turina, M. 2007. Silencing of cryparin, a cell wall hydrophobin, in Cryphonectria parasitica J. Plant Pathol. 89:99-105.

Hansen, D. R., Van Alfen, N. K., Gillies, K., and Powell, W. A. 1985. Naked double-stranded RNA associated with hypovirulence of Endothia parasitica is packaged in fungal vesicles. J. Gen. Virol. 66:2605-2614.

Heiniger, U., and Rigling, D. 1994. Biological control of chestnut blight in Europe. Annu. Rev. Phytopathol. 32:581-599.

Henrich, S., Lindberg, I., Bode, W., and Than, M. E. 2005. Proprotein convertase models based on the crystal structures of furin and kexin: Explanation of their specificity. J. Mol. Biol. 345:211-227.

Iguchi, K., Hirano, H., Kishida, M., Kawasaki, H., and Sakai, T. 1997. Cloning of a protopectinase gene of Trichosporon penicillatum and its expression in Saccharomyces cerevisiae. Microbiology 143:1657-1664.

Jacob-Wilk, D., Turina, M., and Van Alfen, N. K. 2006. Mycovirus Cryphonectria hypovirus 1 elements cofranctionate with trans-golgi network membranes of the fungal host, Cryphonectria parasitica. J. Virol. 80:6588-6596.

Jalving, R., van de Vondervoort, P. J. I., Visser, J., and Schaap, P. J. 2000. Characterization of the kexin-like maturase of Aspergillus niger. Appl. Environ. Microbiol. 66:363-368.

Julius, D., Brake, A., Blair, L., Kunisawa, R., and Thorner, J. 1984. Isolation of the putative structural gene for the lysine-arginine-cleaving endopeptidase required for processing of yeast prepro- $\alpha$-factor. Cell 37:1075-1089.

Kadotani, N., Nakayashiki, H., Tosa, Y., and Mayama, S. 2003. RNA silencing in the phytopathogenic fungus Magnaporthe oryzae. Mol. Plant-Microbe Interact. 16:769-776.

Kazmierczak, P., Pfeiffer, P., Zhang, L., and Van Alfen, N. K. 1996. Transcriptional repression of specific host genes by the mycovirus Cryphonectria hypovirus 1. J. Virol. 70:1137-1142.

Kazmierczak, P., Kim, D. H., Turina, M., and Van Alfen, N. K. 2005. A hydrophobin of the chestnut blight fungus, Cryphonectria parasitica, is required for stromal pustule eruption. Eukaryot. Cell 4:931-936.

Khatib, A. M., Siegfried, G., Chrétien, M., Metrakos, P., and Seidah, N. G. 2002. Proprotein convertases in tumor progression and malignancy: Novel targets in cancer therapy. Am. J. Pathol. 160:1921-1935. 
Komano, H., and Fuller, R. S. 1995. Shared functions in vivo of a glycosyl-phosphatidylinositol-linked aspartyl protease, Mkc7, and the proprotein processing protease Kex 2 in yeast. Proc. Natl. Acad. Sci. U.S.A. 92:10752-10756.

Leatham, G. F., and Stahmann, M. A. 1981. Studies of the laccase of Leutinus edodes: Specificity, localisation and association with the development of fruiting bodies. J. Gen. Microbiol. 125:147-157.

Leibowitz, M. J., and Wickner, R. B. 1976. A chromosomal gene required for killer plasmid expression, mating, and spore maturation in Saccharomyces cerevisiae. Proc. Natl. Acad. Sci. U.S.A. 73:2061-2065.

McCabe, P. M., and Van Alfen, N. K. 2001. Molecular basis of symptom expression by the Cryphonectria Hypovirus. Pages 125-143 in: dsRNA Genetic Elements: Concepts and Applications in Agriculture, Forestry and Medicine. S. M. Tavantzis, ed. CRC Press, Boca Raton, FL, U.S.A.

McCabe, P. M., Pfeiffer, P., and Van Alfen, N. K. 1999. The influence of dsRNA viruses on the biology of plant pathogenic fungi. Trends Microbiol. 7:377-381.

Mizutani, O., Nojima, A., Yamamoto, M., Furukawa, K., Fujioka, T., Yamagata, Y., Abe, K., and Nakajima, T., 2004. Disordered cell integrity signaling caused by disruption of the kex $2 B$ gene in Aspergillus oryzae. Eukaryot. Cell 3:1036-1048.

Nakayashiki, H., Hanada, S., Bao Quoc, N., Kadotani, N., Tosa, Y., and Mayama, S., 2005. RNA silencing as a tool for exploring gene function in ascomycete fungi. Fungal Genet. Biol. 42:275-283.

Napoli, C., Lemieux, C., and Jorgensen, R. 1990. Introduction of a chimeric chalcone synthase gene into petunia results in reversible co-suppression of homologous genes in trans. Plant Cell 2:279-289.

Newhouse, J. R., Hoch, H. C., and MacDonald, W. L. 1983. The ultrastructure of Endothia-parasitica comparison of a virulent with a hypovirulent isolate. Can. J. Bot. 61:389-399.

Newhouse, J. R., MacDonald, W. L., and Hoch, H. C. 1990. Virus-like particles in hyphae and conidia of European hypovirulent dsRNA-containing strains of Cryphonectria parasitica. Can. J. Bot. 68:90-101.

Newport, G., and Agabian, N. 1997. Kex2 influences Candida albicans proteinase secretion and hyphal formation. J. Biol. Chem. 272:28954 28961.

Newport, G., Kuo, A., Flattery, A., Gill, C., Blake, J. J., Kurtz, M. B., Abruzzo, G. K., and Agabian, N. 2003. Inactivation of Kex2p diminishes the virulence of Candida albicans. J. Biol. Chem. 278:1713-1720.

Pignède, G., Wang, H., Fudalej, F., Gaillardin, C., Seman, M., and Nicaud, J. M. 2000. Characterization of an extracellular lipase encoded by LIP2 in Yarrowia lipolytica J. Bacteriol. 182:2802-2810.

Powell, W. A., and Van Alfen, N. K. 1987a. Differential accumulation of poly(A)+ RNA between virulent and double-stranded RNA-induced hypovirulent strains of Cryphonectria (Endothia) parasitica. Mol. Cell. Biol. 7:3688-3693.

Powell, W. A., and Van Alfen, N. K., 1987b. Two nonhomologus viruses of Cryphonectria (Endothia) parasitica reduce accumulation of specific virulence associated polypeptides. J. Bacteriol. 169:5324-5326.

Puhalla, J. E., and Anagnostakis, S. L. 1971. Genetic and nutritional requirements of Endothia parasitica. Phytopathology 61:169-173.

Richard, M., Quijano, R. R., Bezzate, S., Bordon-Pallier, F., and Gaillardin,
C. 2001. Tagging morphogenetic genes by insertional mutagenesis in the yeast Yarrowia lipolytica. J. Bacteriol. 183:3098-3107.

Rigling, D., and Van Alfen, N. K. 1991. Regulation of laccase biosynthesis in the plant-pathogenic fungus Cryphonectria parasitica by doublestranded RNA. J. Bacteriol. 173:8000-8003

Rigling, D., and Van Alfen, N. K. 1993. Extra- and intracellular laccases of the chestnut blight fungus, Cryphonectria parasitica. Appl. Environ. Microbiol. 59:3634-3639.

Rigling, D., Heiniger, U., and Hohl, H. R. 1989. Reduction of laccase activity in dsRNA-containing hypovirulent strains of Cryphonectria (Endothia) parasitica. Phytopathology 79:219-223.

Rockwell, N. C., and Thorner, J. W. 2004. The kindest cuts off all: Crystal structures of Kex2 and furin reveal secrets of precursor processing. Trends Biochem. Sci. 29:80-87.

Romano, N., and Macino, G. 1992. Quelling: Transient inactivation of gene expression in Neurospora crassa by transformation with homologous sequences Mol. Microbiol. 6:3343-3353.

Sambrook, J., Fritsch, E. F., and Maniatis, T., 1989. Molecular Cloning: A Laboratory Manual. Cold Spring Harbor Laboratory Press, Cold Spring Harbor, NY, U.S.A.

Segers, G. C., van Wezel, R., Zhang, X., Hong, Y., and Nuss, D. L. 2006. Hypovirus papain-like protease p29 suppresses RNA silencing in the natural fungal host and in heterologous plant system. Eukaryot. Cell 5:896-904.

Steinberg, G. 2007. On the move: Endosomes in fungal growth and pathogenicity Nat. Rev. Microbiol. 5:309-316.

Taylor, N. A., van de Ven, W. J. M., and Creemers, J. W. M. 2003. Curbing activation: Proprotein convertases in homeostasis and pathology. FASEB J. 17:1215-1227

Thomas, G. 2002. Furin at the cutting edge: From protein traffic to embryogenesis and disease. Nat. Rev. Mol. Cell Biol. 3:753-766.

Tucker, S. L., and Talbot, N. J. 2001. Surface attachment and pre-penetration stage development by plant pathogenic fungi. Annu. Rev. Phytopathol. 39:385-417

Turina, M., Prodi, A., and Van Alfen, N. K. 2003. Role of the Mf1-1 pheromone precursor gene of the filamentous ascomycete Cryphonectria parasitica. Fungal Genet. Biol. 40:242-251.

Venancio, E. J., Daher, B. S., Andrade, R. V., Soares, C. M. A., Silva Pereira, I., and Felipe, M. S. S. 2002. The kex2 gene from the dimorphic and human pathogenic fungus Paracoccidioides brasiliensis. Yeast. 19:1221-1231.

Wösten, H. A. B., Bohlmann, R., Eckerskorn, C., Lottspeich, F., Bölker, M., and Kahmann, R. 1996. A novel class of small amphipathic peptides affect aerial hyphal growth and surface hydrophobicity in Ustilago maydis. EMBO (Eur. Mol. Biol. Organ.) J. 15:4274-4281.

Zhang, L., Villalon, D., Sun, Y., Kazmierczak, P., and Van Alfen, N. K. 1994. Virus-associated down-regulation of the gene encoding cryparin, an abundant cell-surface protein from the chestnut blight fungus, Cryphonectria parasitica. Gene 139:59-64.

Zhang, L., Baasiri, R. A., and Van Alfen, N. K. 1998. Viral repression of fungal pheromone precursor gene expression. Mol. Cell. Biol. 18:953959. 